Тюменский государственный медицинский университет, Тюмень, Российская Федерация

В настоящее время навигационная система медицинского учреждения считается важнейшей частью системы визуализации и одним из базовых критериев качества пространства объектов здравоохранения в концепции бережливого производства. Реализация федерального проекта «Развитие системы оказания первичной медико-санитарной помощи» в рамках национального проекта «Здравоохранение» предусматривает на основе внедрения бережливого производства создание новой модели медицинской организации, оказывающей первичную медико-санитарную помощь, отличительными чертами которой должны стать открытая и вежливая регистратура, сокращение времени ожидания пациентом в очереди, упрощение записи на приём к врачу, уменьшение бумажной документации, комфортные условия для пациента в зонах ожидания и понятная навигация. Благодаря навигационным элементам посетители медицинской организации могут ориентироваться среди помещений, правильно определять необходимый маршрут и перемещаться по выбранному пути движения в здании и по прилегающей территории без существенных отклонений и потерь времени. Планирование маршрута и управление системой ориентирования медицинской организации неразрывно связано с необходимостью определения координат местоположения посетителей и параметров ориентации, осуществляемого в реальном масштабе времени. Развитие средств навигационной системы медицинского учреждения так или иначе сопряжено с оценкой рассогласования текущего и заданного положения человека, оценкой текущего отклонения человека от заданной траектории движения, оценкой текущего значения скорости движения и определения параметров пространственного расположения объектов внешней среды на пути движения человека.

Ключевые слова: бережливое производство; начиональный проект; навигация; навигаџионная система; потери; визуализация; новая модель медицинской организации

\title{
EPIDEMIOLOGICAL SAFETY AS A COMPONENT OF THE OPERATIONAL MANAGEMENT UNIT OF THE INFOCENTER IN INTRODUCTION OF LEAN MANUFACTURING IN A MEDICAL ORGANIZATION THAT PROVIDES PRIMARY HEALTH CARE
}

\author{
A.A. Kurmangulov, Yu.S. Reshetnikova, N.S. Brynza, V.L. Kalinina
}

Tyumen State Medical University, Tyumen, Russian Federation

Currently, the primary health care system is undergoing active reformation. Lean manufacturing technologies are being introduced into the activities of medical organizations that help reduce the 
loss of medical and auxiliary processes. One of the main methods of lean production is visualization, which is implemented in the operational management of a medical organization in the form of creating information centers (InfoCenters) that reflect the main parameters of the activity of a medical organization in the SQDCM system: safety, quality, order execution, costs and a comfortable environment. Criteria of safety of medical activity most relevant for the national healthcare system are parameters of epidemiological safety. A parameter most difficult for indication, but necessary for reflection of epidemiological diagnostics in the InfoCenter is the accident rate at work.

Aim. Generalization of literature data on the possibility of including epidemiological safety parameters into the operational assessment of the InfoCenter. Epidemiological studies conducted in our country in medical organizations of various profiles show an increasing rate of emergency situations among the medical personnel. With this, the system of indication and identification of all emergency cases still remains imperfect, and medical personnel often hide cases of emergency situations.

Conclusion. Introduction of criteria of epidemiological safety into the practical activity of a medical organization as a component of the operational management unit of the InfoCenter will contribute to the formation of functioning and constantly improving system of analysis of the activity of medical organizations, to the control of provision of medical care, and to standardization of invasive procedures to ensure epidemiological safety. The key tasks of the InfoCenter are: focusing the attention of medical organization employees on problems, prompt response to emerging problems and risks, and also ensuring effective communication of all participants of operational meetings in a single information space.

Keywords: lean manufacturing; InfoCenter; visualization; SQDCM system; emergency situations; management; epidemiological safety; new model of medical organization

Бережливое производство (БП) - это управленческая концепция, сформировавшаяся на японском заводе Тоуоtа в первой половине XX века [1,2]. Глобальное распространение и популярность БП среди менеджмента крупных мировых компаний объясняется логичными и понятными базовыми принципами данной концепции, сформированными на основании анализа и адаптации лучших практик управления качеством и изменениями, научной организации труда, маркетинга, стоимостного анализа и экономики [3].

В октябре 2016 года в России на государственном уровне было принято решение o начале широкомасштабного внедрения принципов, положений, философии, а также отдельных методов и инструментов БП в систему здравоохранения. По инициативе Управления по внутренней политике Администрации Президента РФ и при методологической поддержке государственной корпорации по атомной энергии «Росатом» стартовал национальный пилотный проект «Бережливая поликлиника» [4]. Учитывая высокую результативность проекта
«Бережливая поликлиника» в медицинских организациях (МО) пилотных регионов, Указом Президента РФ от 7 мая 2018 г. № 204 «О национальных целях и стратегических задачах развития Российской Федерации на период до 2024 года» отдельным положением отмечена необходимость в обеспечении распространения данного опыта $\mathrm{MO}$ по всей стране с целью оптимизации работы МО, оказывающих первичную медикосанитарную помощь (ПМСП) [1,3].

Как и любая управленческая концепция БП сегодня имеет собственный терминологический аппарат с инструментарием, технологиями и методами. Особое положение среди основных методов концепции БП занимает визуализация. Данный метод показывает себя высокоэффективным средством в решении задач наглядного представления информации для анализа, обеспечения требуемого уровня безопасности, поиска и обнаружения отклонений в процессах, создания условий для принятия быстрых и верных решений, необходимых для оперативного управления в «бережливой» $\mathrm{MO}[1,4]$. 
Концепция БП предлагает новые механизмы и способы визуализации в медицине - это, прежде всего, визуальное управление процессами через SFM, информационные системы, визуализации программ диагностики и немедикаментозного лечения различных заболеваний, а также цветовую кодировку [5-7]. Особое место в ранге возможностей визуализации занимает навигация человека в медицинском учреждении. Различные цветовые, графические, символьные и другие визуальные решения с успехом применяются в навигационных указателях и знаках, а сама система навигации является не только ярчайшим примером метода визуализации, но и эффективным инструментом устранения потерь в концепции БП $[2,8]$.

В широком смысле, навигация - это процесс управления любым объектом, имеющим собственные методы передвижения, в определённом пространстве передвижения $[9,10]$. БП в здравоохранении концепция управления МО, ориентированная на доступность медицинские услуги для населения, минимальное время ожидания приёма в МО, получение информации о состоянии своего здоровья и рекомендаций врача в доступной форме, комфортные условия пребывания в МО $[1,11,12]$. В медицинском учреждении, внедряющем концепцию БП, должно происходить постоянное сокращение всех видов потерь с целью достижения идеальных условий протекания основных и вспомогательных процессов $[13,14]$. С этой точки зрения навигационная система МО может стать эффективным инструментом полного устранения либо минимизации имеющихся потерь.

Базовыми дефинициями, раскрывающими сущность БП, являются понятия «ценности» и «потери» [15]. Ценность - полезность, присущая продукции/услуге с точки зрения потребителя и находящая отражение в цене продаж и рыночном спросе [16]. Прямо противоположным лексическим значением по отношению к понятию «ценности» в концепции БП обладает термин «потери». Потери («муда», в транскрипции ромадзи с яп. «muda» - бесполезность) - любое действие на всех уровнях организации, при осуществлении которого потребляются ресурсы, но не создаётся ценность [17]. Основоположник концепции БП Тайити Оно на заводах Toyota выделял 7 видов потерь: 1) потери из-за перепроизводства; 2) потери времени из-за ожидания; 3) потери из-за лишней обработки; 4) потери из-за лишних движений при выполнении операций; 5) потери из-за лишних запасов; 6) потери при транспортировке; 7) потери из-за выпуска дефектной продукции [2].

В ГОСТ Р 56020-2014 «Бережливое производство. Основные положения и словарь» предлагается разделить все потери на две группы: основные и дополнительные. К основным потерям, согласно данному стандарту, следует отнести все определяемые Т. Оно виды потерь: перепроизводство, избыток запасов, транспортировка, задержки, дополнительная обработка, перемещения и дефекты. Дополнительные виды потерь - это потери, самостоятельно устанавливаемые организацией на основе опыта, накопленного при внедрении концепции БП, и специфики организации собственных процессов. Примеры дополнительных потерь, предлагаемых в стандарте: изменчивость, перегрузка, незадействованный потенциал персонала, трансакционные издержки и недостаточная ценность продукции.

Очевидно, что разные виды потерь в разной степени «чувствительны» к навигационной системе. Например, допускается, что при размещении навигационной системы в МО снизится количество расходуемой бумаги в процессе выдачи письменных указаний по маршруту дальнейшего движения пациента, что, в свою очередь, может привести к снижению уровня запасов бумаги в кабинете специалиста, но вероятность такого сценария не высока. С другой стороны, создаваемая навигационная система может существенно повлиять на снижение лишних перемещений, совершаемых посетителей МО, и чуть меньше на ненужную транспортировку и недостаточную ценность услуги $[8,9]$. 
Очевидно, степень влияния навигационной системы на тот или иной вид потерь, а также получаемые эффекты будут определяться конкретными условиями МO. Например, в презентационном материале Департамента здравоохранения города Москвы «Навигация в городских поликлиниках» приводятся данные о высвобождении до 20\% времени среднего медицинского персонала на стойке информации при создании эффективной навигационной системы в медицинском учреждении [18]. Однако данные сотрудники, так же как и сама стойка информации имеются далеко не во всех МО, поэтому говорить о высвобождении какого-либо времени в этих обстоятельствах преждевременно.

Анализ карт потока создания ценности и диаграмм спагетти текущего состояния в рамках проектов «Бережливая поликлиника» в амбулаторно-поликлинических учреждениях РФ позволяет сделать вывод о значительных перемещениях пациентов по МО в процессе получения различных медицинских услуг $[15,19]$. Отклонение маршрута перемещения посетителя МО от оптимальной траектории движения, а также текущего положения посетителя МО от заданного положения, будут считаться лишними движениями. Дополнительные перемещения посетителей МО приводят не только к прямой трате времени и физических сил, но и к другим негативным последствиям, например, пересечению потоков пациентов, повышению риска травмоопасных ситуаций, снижению общей удовлетворённости пациентов от пребывания в МO.

Вместе с тем необходимо понимать, что лишние движения посетителей МО могут быть связаны не только с несовершенством или с отсутствием навигационной системы. В процессе реализации проектов с внедрением БП и установлением потерь в виде лишних движений посетителей МО необходимо понимать, что дополнительные перемещения пациентов по территории МО могут быть связаны не только с отсутствием либо несовершенством навигационной системы, но и с неправильной маршрутизацией и/или расположением помещений. Маршрутизация - система следования объекта, учитывающая направление движения относительно географических ориентиров или координат, с указанием начальной и конечной точек, а также промежуточных точек, в случае их наличия [8]. Пространство МО - система пространственного расположения помещений (кабинетов, коридоров, зон) на основе внешней и внутренней планировки здания.

И навигация, и маршрутизация, и пространство МО может быть несовершенным, недостаточным, ошибочным или полностью отсутствующим в МО. Попытка выстроить маршрутизацию или навигацию пациентов в здании, в котором кабинеты имеют абсолютно хаотичную нумерацию, а внутренняя планировка коммуникационных помещений больше похожа на лабиринт, обречена на неудачу [9]. Для борьбы с лишними перемещениями посетителей руководству МО необходимо комплексно совершенствовать и навигационную систему, и маршрутизацию различных потоков пациентов, и внутреннюю планировку основных, вспомогательных, хозяйственных, административных, технических помещениях здания медицинского учреждения [9].

Навигационная система МО нацелена на полное устранение либо сокращение лишних перемещений посетителей $\mathrm{MO}$, а также других видов основных и дополнительных потерь БП. Накопленный опыт реализации проектов с внедрением концепции БП в МО позволяет констатировать, что навигационная система может быть эффективным инструментом визуализации. В то же время стоит отметить, что навигационная система в целом и её отдельные элементы могут быть не только средством устранения потерь БП, но и источником этих потерь. Например, размещение в одной области пространства двух идентичных навигационных табличек - это яркий пример перепроизводства; навигационный стенд с большим объёмом нерелевантной информации - фактор, приводящий к ожиданию персонала МО и дополнительным 
действиям пациентов; неправильно расположенные указатели - те же самые лишние движения. Поэтому при создании новой и при совершенствовании существующей навигационной системы в медицинских учреждениях необходимо каждый навигационный элемент проверять на соответствие основным принципам БП. Существенную помощь в этом может оказать понимание основных и дополнительных функций навигационных систем.

На кого должна быть направлена навигационная система? Целевая аудитория системы ориентирования и позиционирования - это категории людей, у которых в процессе нахождения в МО возникает необходимость обращения к навигационной системе для установления своего местонахождения в пространстве, определения цели движения и построения оптимального маршрута к цели движения [9,20]. Посетители МО: пациенты, сопровождающие и родственники пациентов - это и есть основная целевая аудитория любого навигационного элемента. Эффективная навигационная система позволяет человеку быстро, легко и безошибочно ориентироваться как в здании МО (внутренний уровень навигации), так и во всей инфраструктуре объектов здравоохранения (промежуточный и внешний уровни навигации).

Американский исследователь К. Бергер говорит о том, что система ориентирования должна быть рассчитана в первую очередь на впервые оказавшихся или редко бывающих в МО граждан [21]. С этим сложно не согласиться: для людей, с определённой периодичностью приходящих в $\mathrm{MO}$, внутренняя планировка медицинского учреждения и расположение отдельных помещений будут знакомы и визуально понятны - у них не будет необходимости для дополнительного ориентирования в пространстве здания. По этой же причине часто значимость навигационной системы для посетителей МО недооценивается медицинским персоналом. Ежедневно совершая перемещения между различными основными, вспомогательными, коммуникационными помещениями и прекрасно ориентируясь во внутренней схеме здания, они просто не видят проблематики в позиционировании и в ориентировании по МО.

Главное назначение навигационных систем - навигация людей в пространстве. Если же рассматривать современные навигационные системы с позиции онтологического плюрализма, то можно обнаружить и некоторые дополнительные функции навигационных табличек, стендов и наклеек. Эти функции не определяют основное предназначение навигационных элементов и в зависимости от окружающих условий могут иметь разную степень выраженности. Тем не менее, при создании эффективной навигационной системы необходимо всегда учитывать возможности дополнительных каналов взаимодействия с посетителями МО с помощью навигационных элементов [8].

Любая навигационная система всегда выполняет функцию опосредованной коммуникации между персоналом медицинского учреждения и посетителями [9,21]. С точки зрения промышленного дизайна можно выделить два основных типа умозрительных моделей: модель функционирования навигационной системы (модель системы) и модель взаимодействия с ней человека (модель взаимодействия) [22]. Дизайнеры, как правило, создают очень хорошо проработанные модели систем, но часто упускают проработку моделей взаимодействия.

Ставя перед навигационной системой задачу - донести необходимую навигационную информацию до целевой аудитории - дизайнеры и проектировщики, в свою очередь, должны понимать значение самого процесса восприятия посетителями навигационной информации. Как передать навигационную информацию, чтобы посетитель понял её? Сколько усилий и времени придётся при этом посетителю затратить? В какой форме эта информация будет донесена до посетителя? Сможет ли посетитель запомнить эту информацию? С какими трудностями посетитель может столкнуться в процессе восприятия навигационной информации? Какие внешние факторы могут 
повлиять на посетителя во время прочтения информации с навигационного элемента? Вот лишь немногие вопросы, которые должны задать разработчики навигационных систем при их проектировании. Оптимального результата можно добиться, когда разработчики, имея точное и полное представление о модели систем, теоретически и экспериментально проверяют взаимодействии системы с посетителями МО и проектируют навигационные системы, эффективно сочетающие в себе обе модели.

В процессе восприятия посетителями информации навигационная система может выполнять и познавательно-образовательную функцию. Сведения, получаемые посетителем от навигационных указателей, могут не являться для него релевантными в данный момент, но при этом могут оказаться для него полезными в будущем $[8,23]$. В этом случае навигационная система может выступать как инструмент маркетинга медицинского учреждения [24]. Для повышения эффективности рыночного продвижения тех или иных медицинских услуг соответствующим специалистам необходимо владеть приёмами структурирования, зонирования, группировки и акцентирования навигационной информации.

Проектирование дизайна системы визуальной навигации состоит из разностороннего анализа здания МО и составления технического задания на оформление, включающего в себя цветовое, графическое, технологическое решения, эскизычертежи типовых конструкций, схему размещения элементов визуальной коммуникации на объекте [24]. В некоторых региональных руководствах по созданию навигации в МО отдельно рассматривается вопрос психологического воздействия цветов, используемых в навигационных системах.

Дизайн пространства MO заключается в создании условий, обеспечивающих удобное, функциональное и приятное с эстетической точки зрения взаимодействие посетителей и персонала МО в процессе нахождения в МО. Стилистическое оформление навигационной системы может включать в себя и стиль интерьера МO, например, цвет стен и декоративных элементов, геометрические орнаменты покрытий пола и мебели. Система ориентирования может считаться идеальной, если она сочетает функцию прямого взаимодействия посетителей с окружающим пространством и способность усиливать эстетического восприятия МО [21].

Создавая комфортные условия пребывания в МО с быстрым ориентированием в пространстве и возможностью самостоятельно выбрать оптимальный маршрут передвижения, навигационная система повышает лояльность посетителей к медицинскому учреждению [9,25]. Задача дизайнеров графической среды - совместить прагматичное положение ориентирования и безопасности навигационной системы с эмоциональной составляющей.

Система ориентирования может функционировать как средство передачи основной айдентики (от англ. «data name», «identifier» - опознаватель) МО, информирую посетителей о бренде, миссии, ценностях МО [26,27]. Медицинские учреждения, в которых дизайн навигационной системы учитывает отдельные элементы айдентики МО или полностью соответствуют ей, существенно повышают визуальную привлекательность внутренних пространств у посетителей МО [28]. Единый визуально-координированный стиль MO позволяет обеспечивать единство образа бренда в зрительной коммуникации [20]. Руководителям МО необходимо знать о психологических феноменах навигационной айдентики МО для сотрудников и посетителей МO, в том числе различных вариантах так называемого эффекта ожидания (expectation effect): гало-эффектах, хоторнском эффекте, эффекте Пигмалиона и др.

\section{Заключение}

Главная функция навигационной системы заключается в передаче человеку информации о правильном местоположении объектов навигации медицинской организации, об ориентировании человека в окружающем пространстве, а также об оптима- 
льном маршруте. Рационально спроектированная и размещённая система ориентирования может решать и другие задачи, например, создание единого образа МО, формирование зоны психологического комфорта, развитие эффективных коммуникаций между персоналом и посетителями и др. Для медицинских учреждений эти возможности навигационной системы важны и их необходимо использовать руководителям МО и другим организаторам здравоохранения. Интегральная функция навигационной системы для МО как объекта системы здравоохранения определяется эффективностью управления потоками посетителей, что и будет являться основной характеристикой квалиметрической оценки навигационной системы.

\section{Дополнительная информация}

Конфликт интересов. Авторы декларируют отсутствие явных и потенциальных конфликтов интересов, о которых необходимо сообщить в связи с публикацией данной статьи.

Финансирование исследования. Исследование не имело спонсорской поддержки.

\section{Литература}

1. Давыдов А.Ю., Артемьева Г.Б., Перегудова Н.Н. Анализ эффективности первичного профилактического приёма акушером-гинекологом на основе методов бережливого производства // Наука молодых (Eruditio Juvenium). 2020. T. 8, № 2. C. 141-153. doi:10.23888/HMJ202082141-153

2. Канюкова В.П. Бережливое производство: основные инструменты и принципы бережливого производства // Аллея науки. 2018. Т. 1, № 7 (23). C. 642-647. Доступно по: https://alley-science.ru/ domains_data/files/July2018_J/Oblozhka_iyul_1_t om.pdf. Ссылка активна на 15 июля 2020

3. Давыдов А.Ю., Артемьева Г.Б., Хоминец В.В., и др. Оценка удовлетворенности пациентов как индикатор пациентоориентированного подхода в организации акушерско-гинекологической помощи // Наука молодых (Eruditio Juvenium). 2020. T. 8, № 1. C. 38-44. doi:10.23888/HMJ 20208138-44

4. Вергазова Э., Белугина Е. Критерии бережливости закрепят в положении о первичной медпомощи. Что изменится и как подготовиться // Главная медицинская сестра. 2019. № 12. С. 34-47.

5. Курмангулов А.А., Решетникова Ю.С., Брынза Н.С. Эпидемиологическая безопасность как компонент блока оперативного управления инфоцентра при внедрении бережливого производства в медицинскую организацию, оказывающую первичную медико-санитарную помощь // Российский медико-биологический вестник имени академика И.П. Павлова. 2020. Т. 28, № 2. С. 223 233. doi:10.23888/PAVLOVJ2020282223-233

6. Saurabh S.R., Prateek S.S., Jegadeesh R. Exploring the role of color-coding in ensuring delivery of quality-assured healthcare services // Menoufia Medical Journal. 2017. Vol. 30, № 1. P. 3. doi:10.4103/1110-2098.211513

7. Белокрылова Л.В., Дороднева Е.Ф., Шорохова Т.Д., и др. Гендерные особенности пищевых привычек жителей Тюменской области // Медицинская наука и образование Урала. 2015. Т. 16, № 1 (81). C. 68-70.
8. Эффективная система навигации в медицинской организации. М.; 2019.

9. Курмангулов А.А., Брынза Н.С., Решетникова Ю.С., и др. Навигационная система как критерий оценки качества пространства медицинской организации, оказывающей первичную медикосанитарную помощь // Вестник Смоленской государственной медицинской академии. 2019. Т. 18, № 1. C. 206-213.

10. Treuillet S., Royer E. Outdoor/Indoor Vision-Based Localization for Blind Pedestrian Navigation Assistance // International journal of Image and Graphics. 2010. Vol. 10, № 4. P. 481-496. doi:10.1142/S0219467810003937

11. Гродзенский С.Я., Еманаков И.В., Овчинников С.А. Бережливое производство - прошлое и настоящее // Инновационные, информационные и коммуникационные технологии. 2016. № 1. C. 204-207.

12. Латуха О.А. Применение международного опыта бережливого производства в концепции устойчивого развития медицинской организации // Вестник Новосибирского государственного педагогического университета. 2018. Т. 8, № 1. C. 239-254. doi:10.15293/2226-3365.1801.15

13. Сочкова Л.В., Быкова М.М., Ким А.В., и др. Опыт реализации пилотного проекта «Бережливая поликлиника» в поликлинике крупного города // Медицина и организация здравоохранения. 2018. Т. 3, № 2. С. 4-11.

14. Chiarini A., Baccarani C., Mascherpa V. Lean production, Toyota Production System and Kaizen philosophy: A conceptual analysis from the perspective of Zen Buddhism // The TQM Journal. 2018. Vol. 30, № 4. P. 425-438. doi:10.1108/TQM-122017-0178

15. Валиуллина Л.А., Зайцева Е.А. Внедрение принципов бережливого производства в систему здравоохранения ХМАО - Югры // Вестник Сургутского государственного университета. 2017. № 2 (16). C. 33-36.

16. Joelle N. Gleaning Lean Culture // Interdisciplinary Studies in Literature and Environment. 2017. Vol. 
24, № 4. P. 737-752. doi:10.1093/isle/isx071

17. Стеблюк И.Ю. Основные принципы бережливого производства // Экономика: вчера, сегодня, завтра. 2019. Т. 9, № 1А. С. 204-211. doi:10.25799/AR.2019.80.1.021

18. Навигация в городских поликлиниках. Паспорт для главного врача. Доступно по: https://min zdrav.rkomi.ru/content/17977/Презентация\%20по \%20навигации.pdf . Ссылка активна на 01 июня 2020.

19. Монгуш А.В., Кикин П.М. Обзор технологий indoor-навигации // Интерэкспо Гео-Сибирь. 2017. T. 9, № 1. C. 119-123.

20. Tanikawa T., Ohba H., Yagahara A., et al. Patient Accessibility to Hospitals in Winter Road Conditions: GIS-Based Analysis Using Car Navigation Probe Data // Studies in Health Technology and Informatics. 2017. Vol. 245. P. 1383.

21. Бергер К.М. Путеводные знаки. Дизайн графических систем навигации. М.: РИП-холдинг; 2005.

22. Лидвелл У., Холден К., Батлер Д.Ж. Универсальные принципы дизайна. Пер. с англ. А. Мороза. Спб.: Питер; 2014.

23. Назипов Ф.Н. Современные инструменты и принципы бережливого производства // Вестник науки. 2020. Т. 2, № 1 (22). С. 180-186. Доступно по: https://вестник-науки.pф/archiv/journal-1-222.pdf. Ссылка активна на 15 июля 2020.

24. Чернышева Е.Н., Макарова-Коробейникова Е.П. Лин-технологии в управлении медицинской организацией // Вестник Алтайской академии экономики и права. 2019. № 2, Ч. 2. С. 352-357.

25. Soares M., Rebelo F. Ergonomics in Design: methods \& techniques. Taylor \& Francis Group, LLC; 2017.

26. Скопина Е.В., Шустов А.Ю. Исследование технических особенностей и удовлетворенности качеством медицинского обслуживания в поликлиниках по России // Авиценна. 2019. № 53. С. 23-26.

27. Давыденко Е.А. Особенности формирования айдентики и применения цифровых инструментов в продвижении бренда территории // Маркетинг МВА. Маркетинговое управление предприятием. 2019. Т. 10, № 4. С. 91-105.

28. Чашленкова Е.В. Атрибуты айдентики бренда и их роль в формировании стратегии бренда // Аллея науки. 2017. № 7. С. 21-26. Доступно по: https://alley-science.ru/sovremennaya_nauka_i_ee_raz vitie 7 2017/. Ссылка активна на 15 июля 2020.

\section{References}

1. Davydov AYu, Artemyeva GB, Peregudova NN. Analysis of efficiency of primary preventive visit of patient to obstetrician-gynecologist based on lean production methods. Nauka Molodykh (Eruditio Juvenium). 2020;8(2):141-53. (In Russ). doi:10.23888/ HMJ202082141-153

2. Kanyukova VP. Berezhlivoye proizvodstvo: osnovnyye instrumenty i printsipy berezhlivogo proizvodstva. Alleya Nauki. 2018;1(7):642-7. (In Russ). Available at: https://alley-science.ru/
domains_data/files/July2018_J/Oblozhka_iyul_1_ tom.pdf. Accessed: 2020 July 15.

3. Davidov AU, Artem'eva GB, Khominets VV, et al. The evaluation of patient satisfaction as an indicator of patient-bound approach in the organization of obstetric-gynecologic assistance. Nauka Molodykh (Eruditio Juvenium). 2020;8(1):38-44. (In Russ). doi:10.23888/HMJ20208138-44

4. Vergazova E, Belugina E. Kriterii berezhlivosti zakrepyat v polozhenii o pervichnoy medpomoshchi. Chto izmenitsya i kak podgotovit'sya. Glavnaya Meditsinskaya Sestra. 2019;(12):34-47. (In Russ).

5. Kurmangulov AA, Reshetnikova YuS, Brynza NS. Epidemiological safety as a component of the operational management unit of the infocenter in introduction of lean manufacturing in a medical organization that provides primary health care. I.P. Pavlov Russian Medical Biological Herald. 2020;28(2): 223-33. (In Russ). doi:10.23888/PAVLOVJ2020 282223-233

6. Saurabh SR, Prateek SS, Jegadeesh R. Exploring the role of color-coding in ensuring delivery of quality-assured healthcare services. Menoufia Medical Journal. 2017;30(1):3. doi:10.4103/11102098.211513

7. Belokrilova LV, Dorodneva EF, Shorohova TD, et al. Gender features of nutrition habits in Tyumen region population. Meditsinskaya Nauka i Obrazovaniye Urala. 2015;16(1):68-70. (In Russ).

8. Effektivnaya sistema navigatsii $v$ meditsinskoy organizatsii. Moscow; 2019. (In Russ).

9. Kurmangulov AA, Reshetnikova YuS, Brynza NS, et al. Navigation system as a criterion for assessing the quality of medical organization's space providing primary health care. Vestnik Smolenskoy Gosudarstvennoy Medicinskoy Akademii. 2019;18(1): 206-13. (In Russ).

10. Treuillet S, Royer E. Outdoor/Indoor Vision-Based Localization for Blind Pedestrian Navigation Assistance. International journal of Image and Graphics. 2010;10(4):481-96. doi:10.1142/S0219467810003937

11. Grodzenskiy SYa, Emanakov IV, Ovchinnikov SA. Lean production - past and present. Innovatsionnyye, Informatsionnyye i Kommunikatsionnyye Tekhnologii. 2016;(1):204-7. (In Russ).

12. Latuha OA. Application of international experience in lean production within the concept of sustainable development of healthcare setting. Novosibirsk State Pedagogical University Bulletin. 2018;8(1): 239-54. (In Russ). doi:10.15293/2226-3365.1801.15

13. Sochkova LV, Bykova MM, Kim AV, et al. Experience implementation of the pilot project «The therapeutic polyclinic» in the polyclinic of the large city. Medicine and Healthcare Organization. 2018; 3(2):4-11. (In Russ).

14. Chiarini A, Baccarani C, Mascherpa V. Lean production, Toyota Production System and Kaizen philosophy: A conceptual analysis from the perspective of 
Zen Buddhism. The TQM Journal. 2018;30(4):42538. doi:10.1108/TQM-12-2017-0178

15. Valiullina LA, Zaytseva EA. Principles implementation of lean manufacturing into the public health care system of KHMAO - Ugra. Surgut State University Journal. 2017;(2):33-6. (In Russ).

16. Joelle N. Gleaning Lean Culture. Interdisciplinary Studies in Literature and Environment. 2017;24(4): 737-52. doi:10.1093/isle/isx071

17. Steblyuk IYu. Main principles of lean manufacturing. Economics: Yesterday, Today and Tomorrow. 2019;9(1A):204-11. (In Russ). doi:10.25799/ AR.2019.80.1.021

18. Navigatsiya $\mathrm{v}$ gorodskikh poliklinikakh. Pasport dlya glavnogo vracha. https://minzdrav.rkomi. ru/content/17977/Презентация\%20по\%20 навигации.pdf. Accessed: 06.01.2020. (In Russ).

19. Mongush AV, Kikin PM. Review of technologies for indoor navigation. Interexpo Geo-Siberia. 2017;9(1):119-23. (In Russ).

20. Tanikawa T, Ohba H, Yagahara A, et al. Patient Accessibility to Hospitals in Winter Road Conditions: GIS-Based Analysis Using Car Navigation Probe Data. Studies in Health Technology and Informatics. 2017;245:1383.

21. Berger KM. Putevodnyye znaki. Dizayn graficheskikh sistem navigatsii. Moscow: RIP-holding;
2005. (In Russ).

22. Lidwell W, Holden K, Butler DJ. Universal design principles. Per. from English A. Moroz. Saint-Petersburg: Peter; 2014. (In Russ).

23. Nazipov FN. Sovremennyye instrumenty i printsipy berezhlivogo proizvodstva. Vestnik Nauki. 2020;2(1):180-6. Available at: https://вестникнауки.pф/archiv/journal-1-22-2.pdf. Accessed: 2020 July 15. (In Russ).

24. Chernysheva EN, Makarova-Korobeynikova EP. Lin-tekhnologii v upravlenii meditsinskoy organizatsiyey. Vestnik Altayskoy Akademii Ekonomiki $i$ Prava. 2019;(2, Pt 2):352-7. (In Russ).

25. Soares M, Rebelo F. Ergonomics in Design: methods \& techniques. Taylor \& Francis Group, LLC; 2017.

26. Skopina EV, Shustov AE. Research on technical features and quality of medical services in Russian polyclinics. Avicenna. 2019;(53):23-6. (In Russ).

27. Davydenko EA. Features of identity creation and application of digital tools in place brand promotion. Journal Marketing MBA. Marketing Management Firms. 2019;10(4):91-105. (In Russ).

28. Chashlenkova EV. Atributy aydentiki brenda i ikh rol' v formirovanii strategii brenda. Alleya Nauki. 2017;(7):21-6. Available at: https://alley-science.ru/sovremennaya_nauka_i_ee_razvitie_7_2017/. Accessed: 2020 July 15. (In Russ).

\section{Информация об авторах [Authors Info]}

* Курмангулов Альберт Ахметович - к.м.н., руководитель учебного центра бережливых технологий в здравоохранении, доцент кафедры общественного здоровья и здравоохранения, Тюменский государственный медицинский университет, Тюмень, Российская Федерация. E-mail: kurmangulovaa@tyumsmu.ru

SPIN: 1443-3497, ORCID ID: 0000-0003-0850-3422.

Albert A. Kurmangulov - MD, PhD, Head of the Training Center of Lean Technologies in Healthcare, Associate professor of the Department of Public Health Care and Health Care, Tyumen State Medical University, Tyumen, Russian Federation. E-mail: kurmangulovaa@tyumsmu.ru SPIN: 1443-3497, ORCID ID: 0000-0003-0850-3422.

Решетникова Юлия Сергеевна - к.м.н., доцент кафедры общественного здоровья и здравоохранения, Тюменский государственный медицинский университет, Тюмень, Российская Федерация.

SPIN: 1956-8632, ORCID ID: 0000-0001-6726-7103.

Yulia S. Reshetnikova - MD, PhD, Associate Professor of the Department of Public Health and Health Care, Tyumen State Medical University, Tyumen, Russian Federation.

SPIN: 1956-8632, ORCID ID: 0000-0001-6726-7103.

Брынза Наталья Семеновна - д.м.н., заведующий кафедрой общественного здоровья и здравоохранения, Тюменский государственный медицинский университет, Тюмень, Российская Федерация.

SPIN: 8404-2042, ORCID ID: 0000-0001-5985-1780.

Natalya S. Brynza - MD, PhD, Head of the Department of Public Health and Health Care, Tyumen State Medical University, Tyumen, Russian Federation.

SPIN: 8404-2042, ORCID ID: 0000-0001-5985-1780

Калинина Вера Леонидовна - к.м.н., доцент кафедры терапии с курсами эндокринологии, функциональной и ультразвуковой диагностики, Тюменский государственный медицинский университет, Тюмень, Российская Федерация.

SPIN: 8567-4881, ORCID ID: 0000-0002-8264-666X

Vera L. Kalinina - MD, PhD, Associate Professor of the Department of Therapy with Courses of Endocrinology, Functional and Ultrasound Diagnostics, Tyumen State Medical University, Tyumen, Russian Federation.

SPIN: 8567-4881, ORCID ID: 0000-0002-8264-666X.

Цитировать: Курмангулов А.А., Решетникова Ю.С., Брынза Н.С., Калинина В.Л. Роль навигации при внедрении бережливого производства в медицинские организации Российской Федерации // Наука молодых (Eruditio Juvenium). 2021. Т. 9, № 2. С. 280-288. doi:10.23888/HMJ202192280-288

To cite this article: Kurmangulov AA, Reshetnikova YuS, Brynza NS, Kalinina VL. Epidemiological safety as a component of the operational management unit of the InfoCenter in introduction of lean manufacturing in a medical organization that provides primary health care. Science of the young (Eruditio Juvenium). 2021;9(2):280-8. doi:10.23888/HMJ202192280-288

Поступила / Received: 15.07 .2020 Принята в печать / Accepted: 01.06.2021 